\title{
8 \\ Rightmaking and Wrongmaking Properties, Evil, and Theism
}

\author{
Bruce Langtry
}

In 2008 Michael Tooley addressed the problem of evil in his fine contributions to the book Knowledge of God, which he co-authored with Alvin Plantinga. ${ }^{1}$ Here is his main conclusion (MC):

[Quotation 1] Consequently, unless there is countervailing positive evidence in support of the existence of God, or unless belief in the existence of God can be shown to be non-inferentially justified, and in a way that is not easily defeasible, the argument from evil establishes not only that one cannot know that God exists, but also, and even more unhappily, that it is unlikely-indeed, extremely unlikely—that God exists. ${ }^{2}$

Tooley's argument is original and ingenious. These features suffice to make it well worth discussing; a secondary reason for examining it is that some of its leading ideas are likely to be influential via their inclusion in

1 Plantinga and Tooley, 2008. In Tooley, 2012a, 2012b, Tooley revisits parts of the argument from evil I am discussing here. He neither recants anything nor adds anything that affects my treatment of what he says in his 2008 chapters.

${ }^{2}$ Plantinga and Tooley, 2008, 146. Would anyone want to deny the following proposition? If our total evidence did not include empirical truths that provide significant support for the existence of kangaroos, and no one was non-inferentially justified in believing that kangaroos exist, then no one would be justified in believing that kangaroos exist, and it would be extremely unlikely that kangaroos exist. To give MC interest and dialectical bite, one option is to construe it as asserting or implying: The argument from evil establishes that if our total evidence does not include empirical truths that provide significant support for the existence of God, and we are not non-inferentially justified in believing that God exists, then the probability that God exists, relative to our total evidence, is significantly lower than the a priori probability that God exists. 
Tooley's online Stanford Encyclopedia of Philosophy article 'The Problem of Evil'.3

In 1991 Tooley, like William L. Rowe and other authors recently advancing evidentialist arguments from evil against the existence of God, had formulated the issues in axiological terms. ${ }^{4}$ Tooley now believes, however, that such approaches encounter difficulties in connecting the goodness or badness of states of affairs with putative divine actions. ${ }^{5}$ So in Knowledge of God he favours a deontological formulation, which avoids axiological concepts and focuses instead on the moral rightness and moral wrongness of actions and on rightmaking and wrongmaking properties of actions. ${ }^{6}$

Tooley divides his overall deontological argument from evil into three stages. The first two lay the foundations for his argument in the third, and are important for that reason. ${ }^{7}$ The interim conclusion emerging from the first two stages is:

(21) The logical probability that God did not exist at the time of the Lisbon earthquake, given that choosing not to prevent the Lisbon earthquake has a wrongmaking property that we know of, and that there are no rightmaking properties that are known to be counterbalancing, is greater than one half.

Of course, (21) by itself is no threat to theism. The logical probability that kangaroos did not exist at the time of the Lisbon earthquake, given that choosing not to prevent the Lisbon earthquake has a wrongmaking property that we know of, and that there are no rightmaking properties that are known to be counterbalancing, is greater than one half. This truth is not much of an objection to the existence of kangaroos at the time. No doubt Tooley would agree.

3 Tooley, 2012b. $\quad 4$ Tooley, 1991, and (e.g.) Rowe, 1979, 1996.

5 Plantinga and Tooley, 2008, 105-6. In Tooley, 1991, he relied on the premise An omniscient and morally perfect person would prevent the existence of any intrinsically undesirable state of affairs whose prevention it could achieve without either allowing an equal or greater evil, or preventing an equal or greater good. But this premise is subject to decisive objections. I discussed the 1991 paper in Langtry, 2008, 193-6.

6 From now on, for brevity's sake, I will omit the word 'moral' before 'rightness' and 'wrongness', and will omit the word 'morally' before 'right', 'obligatory', 'wrong', 'permissible', and 'impermissible' (except in quotations).

7 Plantinga and Tooley, 2008, 117-22, 126-31, 134-44. 
In the third stage of the overall argument for MC, Tooley employs Rudolf Carnap's inductive logic to argue for the lemma

(G3) If $S_{1}, S_{2}, S_{3}, S_{4}, \ldots S_{n}$ are states of affairs that are preventable, respectively, at times $t_{1}, t_{2}, t_{3}, t_{3}, t_{4}, \ldots t_{n}$, and are such that, for each $S_{i}$, choosing not to prevent $S_{i}$ is an action that, judged by known rightmaking and wrongmaking properties, is prima facie wrong, then the probability, all things considered-including relevant, unknown rightmaking and wrongmaking properties - that there is an omnipotent, omniscient, morally perfect, and omnitemporal person is less than $1 /(n+1)$.

He then argues that $n$ must be very large, and therefore $1 /(n+1)$ must be very small, on the ground that a huge number of people undergo one or more events that, judged by the rightmaking and wrongmaking properties of which we have knowledge, they should not have to suffer. He appears to believe that $\mathrm{G}_{3}$ and a high value for $\mathrm{n}$ together directly yield MC.

\section{Tooley's First Stage: The Introduction of Rightmaking and Wrongmaking Properties}

There is no need here for me to set out in full the twenty-one formal steps of the first stage. It will suffice for my purposes to state four of the premises.

(12) The property of choosing not to prevent an event that will cause the death of more than 50,000 ordinary people is a wrongmaking property of actions, and a very serious one.

(13) The Lisbon earthquake killed approximately 60,000 ordinary people.

(16) For any action whatever, the logical probability that the total wrongmaking properties of the action outweigh the total rightmaking properties-including ones of which we have no knowledge-given that the action has a wrongmaking property that we know of, and that there are no rightmaking properties that are known to be counterbalancing, is greater than one half. 
(17) It is a logically necessary truth that, for any action $C$, if the total wrongmaking properties of the action outweigh the total rightmaking properties-including ones of which we have no knowledge-then action $C$ is morally wrong, all things considered.

I will be arguing throughout this chapter that Tooley lacks a satisfactory account of rightmaking and wrongmaking, and that accordingly his argument from evil runs into trouble at many points. Thus in the rest of this section I will quote what he explicitly says about rightmaking and wrongmaking, and in the next section I will explore his account further. The results of the inquiry will be employed in later sections.

Tooley introduces his qualitative concepts of rightmaking and wrongmaking properties by saying that they can be 'implicitly defined' by the following 'theory' $(\mathrm{T})$ :

[Quotation 2] There are two second-order properties-namely, the property of being a right-making property and the property of being a wrongmaking property-such that if an action possesses at least one property that is a wrongmaking property, and no property that is a rightmaking property, then the action is morally wrong, while if an action possesses at least one property that is a rightmaking property, and no property that is a wrongmaking property, then the action is morally right. ${ }^{8}$

$\mathrm{T}$ is supplemented in the following passages:

[Quotation 3] A complete moral ontology must involve more, however, than qualitative rightmaking and wrongmaking properties, since such properties cannot by themselves determine the status of actions that have both rightmaking and wrongmaking properties, or actions where the objective probabilities of various rightmaking and wrongmaking properties being present have values other than zero and one. If such actions are to have a determinate moral status, there must be quantitative rightmaking and wrongmaking properties, so that there are numbers associated with rightmaking and wrongmaking properties that represent the moral weight, or seriousness, of the properties in question. The idea of quantitative rightmaking and wrongmaking properties can be explicated by whatever method seems most satisfactory for quantitative properties in general. Then, given the idea of quantitative rightmaking and wrongmaking properties, we can say that when an action possesses both rightmaking and wrongmaking properties, its moral status depends on the moral weights

\footnotetext{
${ }^{8}$ Plantinga and Tooley, 2008, 115. The implicit definitions provided by T can, Tooley says, be converted into explicit definitions, using some standard method for defining theoretical terms, such as a Ramsey/Lewis approach.
} 
of the various properties. Thus, for example, if the weight of the wrongmaking properties, taken together, is greater than that of the rightmaking properties, taken together, then the action is morally wrong, all things considered, while if the weight of the rightmaking properties, taken together, is greater than that of the wrongmaking properties, taken together, then the action is either morally permissible, all things considered, or else morally obligatory. ${ }^{9}$

[Quotation 4] In this diagram [Figure 2.1], the region to the right of the vertical axis represents actions that one ought to perform, all things considered, and the farther to the right an action is located, the stronger the obligation to perform it is. Similarly, the region to the left of the vertical axis represents actions that are morally wrong, all things considered, and the farther to the left an action is located, the more wrong it is.... Rightmaking properties will be represented by arrows pointing to the right, and wrongmaking properties by arrows pointing to the left, with the lengths of the arrows representing the seriousness of the properties involved. ${ }^{10}$

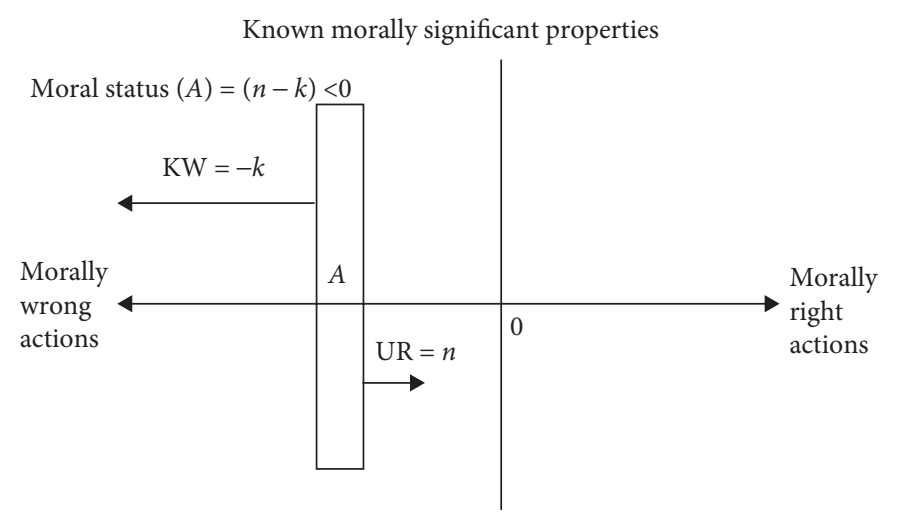

Unknown morally significant properties

[Quotation 5] The proposition expressed by the sentence ' $a$ is a rightmaking property of magnitude $M^{\prime}$ ' can be analyzed in terms of the notion of making an action right to degree $M$. $^{11}$

[Quotation 6] One can ask, "What property did the action of permitting the Lisbon earthquake have that made it morally permissible for God to permit it?... The property of having been permitted by God, who is perfectly good,... while

9 Plantinga and Tooley, 2008, 115-16.

${ }_{10}$ Plantinga and Tooley, 2008, 126-7. Notice a discrepancy between Quotations 3 and 4 . Quotation 4 suggests that all actions are either wrong or obligatory (except those scoring o), and that positive numerical numbers attached to actions measure obligations' degrees of strength. Quotation 3, however, suggests that some positive numerical numbers attached to actions, those in the lower range, pertain to permissible but not obligatory actions and measure how close the actions are to obligatoriness, while those in the higher range order the obligatory actions with respect to strength of obligation.

${ }^{11}$ Plantinga and Tooley, 2008, 239. 
it entails that there must have been a rightmaking property, is not itself a rightmaking property. ${ }^{12}$

\section{The Need for Clarification of the Foregoing Account}

\subsection{Calculating Combined Weights}

In determining the combined weight of an action's total rightmaking properties, and the combined weight of its wrongmaking properties, and thereby calculating a number that represents the moral status of an action, Tooley relies on simple addition and subtraction. The Nullity Argument advanced in section 3 constitutes an objection to this 'additive vector' model. Furthermore, independently of the Nullity Argument, it is apparent that Tooley's model requires a lot of further work to render it a secure footing for his theorizing. For:

(i) Tooley needs to exclude the possibility that some of an action's rightmaking properties have neither greater weight than, nor less weight than, nor the same weight as, some of its other rightmaking properties and some of its wrongmaking properties-for example (some people claim), the properties Enabling one to create great works of art and Causing distress and harm to one's family.

(ii) He also needs to deal with the following technical problem. Let $\mathrm{P}_{1}$ and $\mathrm{P}_{2}$ be wrongmaking properties such that $\mathrm{P}_{1}$ has weight $a$, and $\mathrm{P}_{2}$ has weight $b$, and $\mathrm{P}_{1}$ entails $\mathrm{P}_{2}$, but $\mathrm{P}_{2}$ does not entail $\mathrm{P} 1$-for example, stealing $\$ 30$ and stealing more than $\$ 10$. Are we to say that their combined weight is $a+b$, or would saying this involve double counting of $b$ ? $^{13}$ One option would be to say that in calculating an action's total wrongmaking properties, we should include the weights only of its wrongmaking properties that do not entail any other wrongmaking properties. But adopting this proposal would generate the need for elaborate further explanation, and for revision of Tooley's core argument. For example, the weight of the property of choosing not to prevent an event that will cause the death of more than 50,000

12 Plantinga and Tooley, 2008, 238. $\quad{ }^{13}$ a and b are negative numbers. 
ordinary people would not get included when calculating the moral status of an action, since the action's having this property entails its having the property of choosing not to prevent an event that will cause the death of more than 49,999 ordinary people (and so on).

(iii) Consider a single charitable action that possesses the rightmaking properties helping needy individual 1 , helping needy individual $2, \ldots$ helping needy individual $n$. It is not obvious that the weight of the totality of these $n$ rightmaking properties is equal to the sum of the weights of each property. Tooley needs to argue against the conjecture that, whatever the order in which we take the properties, there is a decline in the marginal contribution of each additional property's weight to the weight of the totality.

\subsection{Rightmaking and Wrongmaking as Essential} Properties of Properties

Although T and Quotations 3-5 do not settle the matter, I will argue that Tooley holds that for all wrongmaking properties $\mathrm{P}$, being wrongmaking and having such-and-such a negative weight are essential properties of P; they do not vary from instance to instance of $\mathrm{P}$, depending on the instance's (first-order) properties and on the context, and do not vary from one time to another time or from one (logically possible) world to another (logically possible) world. ${ }^{14}$ Tooley's holding this view will play an important role in my Nullity Argument. There are two reasons for ascribing it to Tooley:

(a) If he did not hold this view then he would surely see that he should qualify his premise $(12)^{15}$ - for example, so that what it says is that the relevant property is in some circumstances very seriously wrongmaking. He would also surely see that in order to be justified in asserting inferring his (14) Any action of choosing not to prevent the Lisbon earthquake has a very serious wrongmaking property from the conjunction of (12) with (13), he needed to argue that in the actual world if anyone chose not to prevent the Lisbon earthquake, then their action of choosing occurred in circumstances such that

\footnotetext{
14 I am using 'logically possible', 'logically necessary', and 'world' in accordance with the explanations in Langtry, 2008, 40-1.

15 (12), along with premises (13), (16), and (17), was stated at the beginning of my section 1.
} 
the relevant property is in such circumstances wrongmaking. He does not in fact show any signs of recognizing such a need. ${ }^{16}$

(b) If Tooley were to adopt a view contrary to the one I think he holds, substantial revisions would be required to his probabilistic strategy in stage 3 of his overall argument. Tooley proposes to derive a formula that places an upper bound on the probability that none of the $n$ states of affairs $S_{1}, S_{2}, S_{3}, S_{4}, \ldots S_{n}$ mentioned in $G_{3}$ is really such that it is wrong to allow that state of affairs to occur. ${ }^{17}$ The derivation involves taking the number of structure-descriptions involving $S_{1}, S_{2}, S_{3}, S_{4}, \ldots S_{n}$ together with the positive maximal predicates corresponding to the unknown rightmaking and wrongmaking properties, and dividing it by the number of structure-descriptions involving $S_{1}, S_{2}, S_{3}, S_{4}, \ldots S_{n}$ together with the totality of the maximal predicates corresponding to the $\mathrm{k}$ unknown rightmaking and wrongmaking properties. ${ }^{18}$ But if whether or not a property is wrongmaking varied from instance to instance or from world to world, depending on the circumstances, then there would be no number of unknown rightmaking and wrongmaking properties, any more than there is a number of the rainy days, or a number of the people living in poverty. ${ }^{19}$ So Tooley's $\mathrm{k}$ would have no numerical value, not even zero.

\subsection{Parsimony with Respect to Properties}

Although Tooley's argument employs Carnap's inductive logic, which does not rest on any metaphysically serious talk of properties, Tooley says that to formulate key principles underlying his probabilistic calculations

16 Plantinga and Tooley, 2008, 119.

17 Tooley's G3 was stated shortly before the start of section 1 of this chapter.

18 Plantinga and Tooley, 2008, 140-1. A state description is a conjunction of atomic propositions and their negations that specifies, for each actual individual, exactly what properties the individual has, and exactly what properties the individual does not have (pp. 136, 239). A structure description is a set of state descriptions that differ only with respect to a permutation of the individuals involved (p. 137). A predicate is maximal with respect to a set of properties if and only if, when applied to an individual, it indicates, for every property in the set, whether this individual has the property or not (p. 138). A Q-predicate is maximal with respect to the set of unknown rightmaking and wrongmaking properties. And a Q-predicate is positive if and only if, considering only unknown rightmaking and wrongmaking properties, any action to which the predicate applies is neither morally neutral nor impermissible (p. 140).

19 There is, of course, a number of the days in the 19th century on which rain fell on at least part of the area of land now occupied by Canberra, and there is a number of people 
he needs a sparse theory of properties as genuine universals. ${ }^{20} \mathrm{He}$ tells us that such a theory will rule out disjunctive universals and negative ones. ${ }^{21} \mathrm{He}$ declares that the property of always choosing to do what is right is a genuine universal, and he evidently thinks that Being a rightmaking property and Being a wrongmaking property, and Choosing not to prevent an event that will cause the deaths of more than 50,000 ordinary people are genuine universals too. ${ }^{22}$

These examples, however, leave it unclear what will be sparse about a theory of properties suitable for Tooley's purposes. The word 'sparse' is usually reserved for theories which affirm both that the distribution of genuine universals amongst the individuals in the world constitutes a minimal base on which all contingent truths supervene. If Tooley really needs a sparse theory, he needs one that, amongst other things,

- counts in the examples given in the previous paragraph while ruling out a great many putative properties,

- tells us whether there are uninstantiated universals, and

- helps us to classify, for example, 'Being a war' and 'Constituting income tax evasion' as either each denoting a genuine universal, or not, as the case may be.

Tooley does not provide such a theory, or endorse anyone else's. He identifies David Armstrong's theory as a sparse one. He cannot adopt it, given that Armstrong would deny that 'being a rightmaking property' and 'being a wrongmaking property' denote genuine (second-order) universals. $^{23}$

I will now argue that Tooley is correct in supposing that he really does need a sparse theory of properties, an unusual one that allows him to say that Being a rightmaking property and Being a wrongmaking property are properties. Suppose that he instead adopts a very liberal attitude to his own talk of properties, not regarding it as metaphysically serious. In that case, he can say that to any truth constitutively (not merely

who would be classified as living in poverty in Australia in December 2013, according to at least one of the alternative, widely used 'poverty lines'.

${ }^{20}$ Plantinga and Tooley, 2008, 236-7. ${ }^{21}$ Plantinga, 2008, 237.

22 Plantinga and Tooley, 2008, 237, 239, 119.

${ }^{23}$ Cf. Armstrong's argument for the principle that that all higher-order properties are formal properties, in Armstrong (1978, 138-40). 
epistemically) relevant to the rightness or wrongness of an action there corresponds some rightmaking or wrongmaking property of the action; furthermore, he can suppose that there are uninstantiated rightmaking and wrongmaking properties, such as Shooting the last trilobite. Given a liberal view, however, it will be hard to reject the proposition that there are infinitely many unknown rightmaking and wrongmaking properties. For example, let $\mathrm{R}$ be an unknown relation such that Your bringing it about that you stand in relation $R$ to one or more other people is wrongmaking, and such that (other things being equal) the more people to whom you stand in relation $\mathrm{R}$, the more seriously wrong is your bringing it about that you stand in relation $\mathrm{R}$ to them. In that case, there will be an infinite number of wrongmaking properties $x$ 's bringing it about that $x$ stands in relation $R$ to one person, and $x$ 's bringing it about that $x$ stands in relation $R$ to two persons, and so on without end.

Now consider, again, Tooley's calculation of an upper bound on the probability that none of the $n$ states of affairs $S_{1}, S_{2}, S_{3}, S_{4}, \ldots S_{n}$ mentioned in $\mathrm{G}_{3}$ is really such that it is wrong to allow that state of affairs to occur. ${ }^{24}$ If there are infinitely many unknown rightmaking and wrongmaking properties then Tooley's $\mathrm{k}$ is infinitely large, and the formula Tooley derives for the value of $\mathrm{P}(\mathrm{k}, \mathrm{n})$, namely

$$
\frac{(2 \mathrm{k}-1)(2 \mathrm{k}-2) \cdots(\mathrm{k}+1)(\mathrm{k})}{(\mathrm{n}+2 \mathrm{k}-1)(\mathrm{n}+2 \mathrm{k}-2) \cdots(\mathrm{n}+\mathrm{k})}
$$

involves dividing infinity by infinity, an illegitimate operation that can yield no numerical value at all for $\mathrm{P}(\mathrm{k}, \mathrm{n})$.

\section{Objections to Tooley's Account of Rightmaking and Wrongmaking Properties, and to his Premise (17)}

\subsection{The Nullity Argument}

Let $\mathrm{A}_{1}$ be the property of choosing not to prevent an event that will cause the death of more than 50,000 ordinary people. As I have already indicated, Tooley holds that

\footnotetext{
24 Plantinga and Tooley, 2008, 140-1.
} 
(a) A1 is a very serious wrongmaking property, in the actual world and in all other worlds in which it exists.

And theory T implies that

( $\beta$ ) If an action possesses $A_{1}$, and $A_{1}$ is wrongmaking, and the action possesses no rightmaking properties, then the action is wrong.

Let us call the following line of thought the Nullity Argument. Its upshot is that Tooley cannot plausibly assert both $\alpha$ and $\beta$. It involves my describing a possible world, $\mathrm{W}_{1}$, in which some action possesses $\mathrm{A} 1$, and has no rightmaking properties, and is not wrong. ${ }^{25} \mathrm{I}$ will be working from inside Tooley's theory, in order to undermine it.

In $\mathrm{W}_{1}$ there was a time at which the entire human population consisted of exactly 51,00o human beings, and some event instantaneously annihilated them all. One microsecond later another event occurred which would have killed everyone if the first event had not done so already. There is some non-divine, non-human agent-call her 'Alia'who could have prevented the first event yet chose not to. She could not have prevented the second event. Alia did not cause either event. She had not entered into any prior special relationship with anyone, or commitment to anyone, in virtue of which she acquired an obligation to prevent any event which she could prevent and whose occurrence would cause the death of any of the 51,00o. It follows that Alia's action-token, X, of choosing not to prevent the first event possesses A1 but no wrongmaking properties not entailed by A1. X does not possess the wrongmaking property Choosing not to prevent an event that will cause great suffering to many ordinary people because the event killed everyone so fast that it gave no one any time to suffer. $\mathrm{X}$ does not possess the wrongmaking property Choosing not to prevent an event that will shorten, by significant amounts, the lifespans of many ordinary people because if the event in question, the first event, had not occurred then the 51,00o people would have lived for only one more microsecond. Similarly for the properties Choosing not to prevent an event that will cause many people to undergo serious mutilation or dysfunction, and Choosing not to prevent an event that will preclude fulfilment of many human desires that would otherwise

${ }^{25}$ It is epistemically possible that $\mathrm{W}_{1}$ is the actual world, and that the relevant events will occur many thousands of years from now. 
have been fulfilled, and Choosing not to prevent an event that will leave many children unparented for a significant period of time. (For brevity's sake, I'll call these five specified, absent properties 'Ai's expected concomitants'.)

I infer from the foregoing description of $\mathrm{W}_{1}$ that in $\mathrm{W}_{1} \mathrm{X}$ is not wrong. Look at it this way. In general, if an agent were to have the power to prevent an event that would cause the death of more than 50,00o people, what reasons would he or she have, morally speaking, for doing so? Perhaps the agent has duties arising from special ties to individuals, or from his or her own past actions. I have already stipulated that in $\mathrm{W}_{1}$ this consideration does not apply. In general, the sudden death of more than 50,000 people would be a very bad event, and agents have a reason to prevent a very bad event. In what respects would the event be bad? Typically, the sudden death of more than 50,0oo people would deprive these people of good experiences and achievements they would otherwise have had, it would preclude fulfilment of many human desires that would otherwise have been fulfilled, and so on. But this truth, which would in general provide strong reasons for a suitably powerful and well-located agent to prevent an event that would cause the death of more than 50,000 people, is not applicable to the circumstances in $\mathrm{W}_{1}$, and so does not generate a reason for Alia, in $\mathrm{W}_{1}$, to prevent the fatal event (and therefore to prevent the humans' all dying one microsecond earlier than was otherwise inevitable).

I now declare that in $\mathrm{W}_{1}$ Alia's action $\mathrm{X}$ has no rightmaking properties. This is an additional stipulation concerning $\mathrm{W}_{1}$, rather than a consequence of earlier stipulations. We should consider two objections to its legitimacy. The first is that, necessarily, any action whatever has some rightmaking property, even if it happens to be very feebly rightmaking. Tooley must reject this claim. For if it were true then the conditional If an action possesses at least one property that is a wrongmaking property, and no property that is a rightmaking property, then the action is right (sic) would be necessarily true, in virtue of the necessary falsity of its antecedent. Thus $\mathrm{T}$ would fail to provide a coherent definition of 'rightmaking property' and 'wrongmaking property'.

The second objection is that in $\mathrm{W}_{1}$ the state of affairs consisting in X's lack of Ai's expected concomitants corresponds to the property (A2) Lacking A1's five specified expected concomitants, and $\mathrm{A}_{2}$ is a rightmaking property of X. Not so. If Tooley were to advance this objection 
himself, and were to agree that in $\mathrm{W}_{1} \mathrm{X}$ is either not wrong or not seriously wrong, he would have to say that A2 counterbalances, at least to a great extent and perhaps even completely, the great wrongmaking weight of A1. In that case, Tooley would have to say that A2 has great rightmaking weight, and (as I pointed out in section 2.2) has it in every context in which it is instantiated. But this is not so. For example, your stealing \$10 would possess A2, but this fact would have no tendency to make your action right or to reduce your action's degree of wrongness. Furthermore, consider a world $\mathrm{W}_{2}$, in which the Lisbon earthquake occurs and the action Choosing not to prevent the Lisbon earthquake has A2 and has neither A1 nor any other wrongmaking property-for example, because a year before the earthquake some other natural disaster had rendered Lisbon uninhabitable by humans and by sentient animals for the following few years. If $\mathrm{A}_{2}$ has great rightmaking weight in $\mathrm{W}_{1}$ then it has great rightmaking weight in $\mathrm{W}_{2}$. In that case, in $\mathrm{W}_{2}$ the action Choosing not to prevent the Lisbon earthquake is fairly strongly obligatory. This consequence is surely unacceptable. So we should reject the thought that $\mathrm{A}_{2}$ is a rightmaking property. In that case, in $\mathrm{W}_{1} \mathrm{~A}_{2}$ does not outweigh A1.

I have argued in the last few paragraphs that Alia's action X possesses no rightmaking properties and yet is not wrong. It follows, via $\mathrm{T}$, that $\mathrm{X}$ does not possess any wrongmaking properties. How can this be, given that $\mathrm{X}$ possesses $\mathrm{A} 1$ ?

We should conclude, contrary to Tooley's overall position, that X's lacking Al's expected concomitants removes or nullifies what would otherwise be the moral weight of X's possessing A1 (and whatever wrongmaking properties are entailed by $\mathrm{A} 1$ ).

This conclusion fits nicely into a broader context. If there are rightmaking and wrongmaking properties at all, there are other, quite different ways in which a rightmaking or wrongmaking property can be nullified, or its weight considerably reduced.

Suppose that Edith intentionally presses a button, and that her action (i.e. action-token) has the wrongmaking property Being the triggering cause of a bomb explosion in a crowded restaurant. It also has the property Being performed by someone captured by terrorists who dosed her heavily with drugs suitable for inducing compliance with their instructions. Since an action is wrong only if the agent is morally responsible for it, and since, let us suppose, Edith was not morally responsible for her action, it 
was not wrong. ${ }^{26}$ Now Being performed by someone captured by terrorists who dosed him/her heavily with drugs suitable for inducing compliance with their instructions is not a rightmaking property as judged by T. It has no tendency to confer rightness on Edith's action-token. Indeed, it bestows the property Being neither permissible nor impermissible. Since it is has zero rightmaking weight, it does not counterbalance the wrongmaking property Edith's action-token possesses. Instead, it nullifies the wrongmaking property. Presumably there are cases like Edith's in the actual world.

Here is another example. Suppose that Fran speaks to Gordon. Her action possesses the property Being an offer of a drink of water to a thirsty man. It also possesses the property Being an offer of a drink of water to a man who is carrying a full bottle of water in his backpack. The latter property is not a wrongmaking property of Fran's action. It reduces, in this instance, the rightmaking weight of the first property.

The actions of Alia and of Edith are logically possible cases in which an action possesses at least one wrongmaking property and no rightmaking property, and yet is not wrong. Since if T is true then it is necessarily true, it follows that $\mathrm{T}$ is false.

The actions of Alia and of Edith are direct counterexamples to Tooley's (17).

\subsection{Attempts to Evade the Nullity Argument by Revising the Argument from Evil}

Can Tooley respond to the Alia counterexample by abandoning his view that $\mathrm{A}_{1}$ is a wrongmaking property? Doing so would require him to replace his premises (12) and (13) as currently formulated with revised versions which both involve some property whose status as genuinely wrongmaking (judged using $\mathrm{T}$ ) is not threatened by considerations similar to those raised and also jointly entail (14). If he can do so, then the Nullity Argument will fail to establish that $\mathrm{T}$ is false. Here is a proposal:

(12a) The property of choosing not to prevent an event that possesses $A 1$ and $A 1$ 's five specified expected concomitants is a wrongmaking property of actions, and a very serious one, and

26 After all, we do not ascribe either rightness or wrongness to the actions of seagulls, sharks, or human babies. 
(13a) The Lisbon earthquake possessed $A 1$ and $A 1$ 's five specified expected concomitants.

The proposal fails. It involves the idea that the Nullity Argument has a false premise, because $\mathrm{A} 1$ is not a wrongmaking property as defined by T. But even if $A_{1}$ has no wrongmaking weight in the context of the specified event in $W_{1}$, there are other contexts in which A1 does have wrongmaking weight. For example, consider a world $\mathrm{W}_{3}$ that is similar to $\mathrm{W}_{1}$ except that in $\mathrm{W}_{3}$ Alia, a few days before the calamitous first event, made a solemn promise to prevent any event that she could prevent and that would cause the deaths of human beings. $\mathrm{In}_{3}$ the fact that Alia's action of choosing, X, possesses A1 counts (constitutively and not merely epistemically) against $\mathrm{X}$. True, $\mathrm{X}$ has the wrongmaking property (B1) making a choice that will involve breaking a solemn promise to prevent any event that she could prevent and that will cause the deaths of human beings, and in the absence of counterbalancing rightmaking properties X's having B1 will suffice to make X wrong. Nevertheless, as Quotation 4 indicates, Tooley holds that some impermissible actions are much more seriously wrong than others. There are many ways in which Alia could have broken her promise. In $\mathrm{W}_{3} \mathrm{X}$ is a more serious violation of obligation, and so more seriously wrong, in virtue of $X$ 's having $A 1$ in addition to $B 1$, even though X lacks A1's expected concomitants. That is, X's having A1 is constitutively, and not merely causally or epistemically, related to X's degree of wrongness. In that case, how can Tooley avoid acknowledging that in $\mathrm{W}_{3} \mathrm{~A}_{1}$ is wrongmaking?

So Tooley faces a dilemma: Either A1 is a wrongmaking property or it is not. If $\mathrm{A}_{1}$ is a wrongmaking property then the Nullity Argument establishes that it is logically possible (e.g. it is true in $W_{1}$ ) that there be actions that possess wrongmaking properties and no rightmaking properties and yet are not wrong. In that case, given that if a property is wrongmaking then it is wrongmaking in all worlds in which it is instantiated, we can infer that $\mathrm{T}$ is false, and premise (17) is false. If $\mathrm{A} 1$ is not a wrongmaking property then it is logically possible (e.g. it is true in $\mathrm{W}_{3}$ ) that an action's having a certain property counts constitutively in favour of the action's being more seriously wrong than it otherwise would have been, even though the property is not wrongmaking, as defined by Tooley. Unless Tooley has some argument for saying that such a property (or a conjunction of such properties) could never either outweigh 
or nullify the totality of an action's rightmaking properties, T cannot underwrite a theory of rightmaking and wrongmaking, and (17) is false.

Could Tooley save at least some key features of his approach by making revisions much more far-reaching than the replacement of (12) by (12a)? Could he adopt the view that in general being wrongmaking and having such-and-such a weight are features of a property that vary from world to world, and from situation from situation within worlds? I discussed this question in section 2.2, and pointed out that if Tooley adopted it then major revisions to his argument for MC would be required-not only in the first two stages but also in the crucial third stage. A hope that a new account of rightmaking and wrongmaking would succeed in delivering some principle similar to $\mathrm{G}_{3}$ would be merely speculative.

\section{Tooley's Deontological Argument: Second Stage}

Tooley's second stage consists of a justification for his probabilistic premise (16), which he describes as 'very controversial'. ${ }^{27}$ Here is (16) again:

For any action whatever, the logical probability that the total wrongmaking properties of the action outweigh the total rightmaking properties-including ones of which we have no knowledge - given that the action has a wrongmaking property that we know of, and that there are no rightmaking properties that are known to be counterbalancing, is greater than one half.

I will provide a counterexample to (16). The following argument is prompted by the thought that, although there are possible worlds in which you have little background or skill in philosophy yet acquire an understanding of this chapter-for example, someone spends ten hours explaining it to you-your actual current action-token of acquiring an understanding of this chapter is essentially an exercise by you of considerable philosophical skill, employing an extensive background knowledge of philosophy. The argument employs Tooley's own premise (17), and is accordingly a kind of reductio of his position.

(a) It is logically necessary that if God exists and is omnipotent, omniscient, and perfectly good, then, even if it is contingent that

${ }^{27}$ Plantinga and Tooley, 2008, 120. He says that (16) 'lies at the heart of the present formulation of the argument from evil'. 
God is perfectly good, every action performed by God is essentially both performed by God and essentially not wrong. ${ }^{28}$ [premise]

(b) It is logically necessary that if an action is performed by God and is compatible with God's perfect goodness then its total wrongmaking properties do not outweigh its total rightmaking properties. [from (a), Tooley's (17)]

(c) There is some possible world in which God exists and is omnipotent, omniscient, and perfectly good, and in which there is an action $\mathrm{Y}$, performed by God, such that $\mathrm{Y}$ has a known wrongmaking property and has no rightmaking properties that we know of and that we know to be counterbalancing. ${ }^{29}$ [premise]

(d) It is logically necessary that if Y exists then $\mathrm{Y}$ is essentially performed by God and is essentially compatible with God's perfect goodness. [from (a), (c)]

(e) It is logically necessary that if action $\mathrm{Y}$ exists and has a known wrongmaking property, and has no has no rightmaking properties that we know of and that we know to be counterbalancing, then $\mathrm{Y}$ is performed by God and is compatible with God's perfect goodness. [from (d)]

(f) It is logically necessary that if action $\mathrm{Y}$ exists and has a known wrongmaking property, and has no rightmaking properties that we know of and that we know to be counterbalancing, then Y's total wrongmaking properties do not outweigh its total rightmaking properties. [from (e), (b)]

(g) The logical probability that Y's total wrongmaking properties outweigh its total rightmaking properties, given that $Y$ exists and has a known wrongmaking property, and that $\mathrm{Y}$ is has no rightmaking properties that we know of and that we know to be counterbalancing, is zero. [from (f)]

(h) (16), if true, is necessarily true. [premise]

(i) (16) is false. [from (g), (h)]

\footnotetext{
${ }^{28}$ In premise (a) and elsewhere in (a)-(i), I am using 'action' as an abbreviation of 'action-token'. This seems the sensible way to interpret the occurrence of 'action' in, say, Tooley's premise (12).

${ }^{29}$ (c) follows from the conjunction of Tooley's premise (16) with the proposition that it is logically possible that God exists and is an omnipotent, omniscient, and perfectly good being.
} 
My criticisms of Tooley's account of the concepts of rightmaking and wrongmaking properties suffice to undermine Tooley's reasoning in favour of (16).

\section{Tooley's Deontological Argument: Third Stage}

In the third stage of his deontological argument, Tooley employs Carnap's inductive logic to argue that

(G3) If $S_{1}, S_{2}, S_{3}, S_{4}, \ldots S_{n}$ are states of affairs that are preventable, respectively, at times $t_{1}, t_{2}, t_{3}, t_{3}, t_{4}, \ldots t_{n}$, and are such that, for each $S_{i}$, choosing not to prevent $S_{\mathrm{i}}$ is an action that, judged by known rightmaking and wrongmaking properties, is prima facie wrong, then the probability, all things considered-including relevant, unknown rightmaking and wrongmaking properties-that there is an omnipotent, omniscient, morally perfect, and omnitemporal person is less than $1 /(n+1)$.

He argues that $n$ must be very large, and therefore $1 /(n+1)$ must be very small. ${ }^{30} \mathrm{He}$ appears to believe that $\mathrm{G}_{3}$ and a high value for $\mathrm{n}$ together directly yield MC, which I stated at the beginning of this chapter:

Consequently, unless there is countervailing evidence in support of the existence of God, or unless belief in God can be shown to be non-inferentially justified, and in way that is not easily defeasible, the argument from evil establishes not only that one cannot know that God exists, but also, and even more unhappily, that it is unlikely—indeed, extremely unlikely—-that God exists. ${ }^{31}$

It should already be apparent that Tooley's argument for $\mathrm{G}_{3}$ is unsatisfactory as it stands. First, I pointed out in section $\mathbf{2 . 2}$ that Tooley's calculation of $\mathrm{G}_{3}$ depends on the hidden assumption that being wrongmaking, and having the negative weight it has, are essential features of a property that has them. The Nullity Argument employs this very

${ }^{30}$ Plantinga and Tooley, 2008, 142.

${ }^{31}$ Plantinga and Tooley, 2008, 146. What does it take for evidence $e_{1}$ for God exists to be countervailing against evidence $\mathrm{e}_{2}$ for God does not exist, given background evidence B? We should not be distracted by the question whether $\mathrm{P}\left(\right.$ God exists $\left./ \mathrm{e}_{1} \& \mathrm{~B}\right)>\mathrm{P}($ God does not exist $\left./ \mathrm{e}_{2} \& \mathrm{~B}\right)$, but should focus instead on whether $\mathrm{P}\left(\mathrm{God}\right.$ exists/ $\left./ \mathrm{e}_{1} \& \mathrm{e}_{2} \& \mathrm{~B}\right)>\mathrm{P}(\operatorname{God}$ does not exist/ $\left.\mathrm{e}_{1} \& \mathrm{e}_{2} \& B\right)$. 
assumption (along with other things Tooley says about rightmaking and wrongmaking properties) to argue that wrongmaking property can be nullified, or its weight considerably reduced, by a property that is not rightmaking. If this is so, then in calculating the probability all things considered that God exists, Tooley needs to take into account not only known relevant rightmaking and wrongmaking properties of a particular action of choosing, $\mathrm{D}_{\mathrm{i}}$, of a state of affairs $\mathrm{S}_{\mathrm{i}}$, but also any other known properties of $D_{i}$ that are constitutively relevant to its rightness or wrongness. One can speculate about what a reworked calculation would be like, but given that the foregoing points threaten the adequacy of his very definitions of 'rightmaking property' and 'wrongmaking property', what would be required is for Tooley to reconceptualize the issues.

Secondly, section 2.3 gives rise to a second line of thought with the same general upshot. Either Tooley takes a very liberal approach to his talk of properties-for example, regarding 'x possesses Fness' as merely a stylistic variant of ' $\mathrm{x}$ is $\mathrm{F}$ '-or else he adopts a metaphysically serious theory of properties that is sparse and yet recognizes the existence of first-order properties such as Choosing not to prevent the death of many people and second-order properties such as Being rightmaking. If he chooses the first alternative, he will have to acknowledge that that there are infinitely many unknown rightmaking and wrongmaking properties. In that case, his derivation of $\mathrm{G}_{3}$ will fail in the way I explained in section 2.3. If Tooley chooses the second alternative, he needs to explain how the rich array of moral truths about an action is grounded in the sparse array of morally relevant properties of the action. He must allay doubts as to whether there are truths constitutively relevant to the rightness or wrongness of an action to which there do not correspond any of the action's rightmaking or wrongmaking properties (or any combination of its rightmaking or wrongmaking properties). If there are such truths then he needs to take account of them in his argument for MC; he has not done so.

I will spend the rest of this section giving other reasons for believing that MC is false-at least, that it is false if 'the argument from evil' refers to the deontological argument stated and defended in Tooley's chapters in Knowledge of God.

Let us focus on $\mathrm{G}_{3}$ and its relation to MC. Since (16) and (21) explicitly involve logical probability, and since Tooley is employing Carnapian 
inductive logic, it is safe to say that he intends the consequent of $\mathrm{G}_{3}$ to involve logical probability. Logical probability statements are either necessarily true or necessarily false, and so their truth-value is independent of contingent truths. The antecedent of $\mathrm{G}_{3}$ is contingent, since it entails the existence of actions of the kind it describes. Therefore the logical probability statement constituting G3's consequent is independent of G3's antecedent. In that case, Tooley needs to bring the antecedent inside the logical probability operator, somehow.

G3 cannot, however, be straightforwardly identified with the proposition

(G3a) The logical probability that there is an omnipotent, omniscient, morally perfect, and omnitemporal person, given that there exist states of affairs $\mathrm{S}_{1}, \mathrm{~S}_{2}, \mathrm{~S}_{3}, \mathrm{~S}_{4}, \ldots \mathrm{S}_{\mathrm{n}}$ which are preventable, respectively, at times $t_{1}, t_{2}, t_{3}, t_{3}, t_{4}, \ldots t_{n}$, and are such that, for each $S_{i}$, choosing not to prevent $\mathrm{S}_{\mathrm{i}}$ is an action that, judged by known rightmaking and wrongmaking properties, is prima facie wrong, is less than $1 /(n+1)$.

For this leaves out the idea, present in $\mathrm{G}_{3}$ itself, of probability all things considered. Nevertheless, adding the words 'and given also that the foregoing is our total evidence' immediately before the words 'is prima facie wrong' will achieve nothing that was not already achieved by G3a as it stands. ${ }^{32}$

Obviously, if we know that $\mathrm{G}_{3}$ a is true, then in possible worlds in which we know that our total evidence is that there exist states of affairs $S_{1}, S_{2}$, $S_{3}, S_{4}, \ldots S_{n}$ that are preventable, respectively, at times $t_{1}, t_{2}, t_{3}, t_{3}, t_{4}, \ldots t_{n}$, and are such that, for each $S_{i}$, choosing not to prevent $S_{i}$ is an action that, judged by known rightmaking and wrongmaking properties, is prima facie wrong, we can properly infer that the logical probability, relative to our total evidence, that there is an omnipotent, omniscient, morally perfect, and omnitemporal person, is less than $1 /(n+1){ }^{33}$

But it is obvious that none of these worlds is the actual world. In the actual world, we know a vast amount more that has a bearing on whether

32 In general, leaving aside special cases such as ones in which $e$ is our total evidence is a conjunct of $h, \mathrm{P}(\mathrm{h} / \mathrm{e})=\mathrm{N}$ if and only if $\mathrm{P}(\mathrm{h} /(\mathrm{e} \&(\mathrm{e}$ is our total evidence $))=\mathrm{N}$.

${ }^{33}$ Who are the people to whom each Si's known rightmaking and wrongmaking properties are known? The argument will not work if e.g. a different knower is involved for each event. Let us take the knowers to be the readers of this book. Thus all the Si, and all their respective known rightmaking and wrongmaking properties, are known by every reader of this book. 
God exists. In fairness to Tooley, we should remember that his main conclusion MC (Quotation 1) is carefully qualified: it does not purport to cover either the epistemic possibility that there is countervailing positive evidence in support of the existence of God or the epistemic possibility that belief in the existence of God can be shown to be non-inferentially justified. ${ }^{34}$ We should also remember that he thinks that our total evidence includes such propositions as $n>10^{9}$ and The Lisbon earthquake killed approximately 60,000 people. ${ }^{35}$

Nevertheless, Tooley also believes that our total evidence includes no propositions that overthrow or greatly weaken the strong prima facie justification, provided by his argument for $\mathrm{G}_{3}$, of the proposition Anyone's allowing (or, alternatively, God's allowing, if God exists) all of $S_{1}, S_{2}, S_{3}, S_{4}, \ldots S_{n}$ would be wrong. Of course I have been denying that the argument for $\mathrm{G}_{3}$ does provide strong prima facie justification of the latter proposition, but I will suspend this denial for a moment, for the sake of discussion. There remain important countervailing considerations that Tooley needs to consider before reaffirming his belief.

In God, the Best and Evil, for example, I argued that it is permissible for God, if he exists, to allow there to be a lot of human suffering and dysfunction, and also a lot of wrongdoing. Furthermore, I argued that it is permissible for God, if he exists, to allow suffering and dysfunction to be distributed unequally, and in ways that do not reflect individuals' moral standing. When Tooley infers MC from $\mathrm{G}_{3}$ together with a high value for $n$, he seems not to notice the need to seriously consider claims such as mine. (This is not surprising, given that it would be a complicated business to map my claims onto propositions about rightmaking and wrongmaking properties of a divine decision to not prevent the Lisbon earthquake.) Obviously, if we have strong reasons to believe that God's allowing a great many of $S_{1}, S_{2}, S_{3}, S_{4}, \ldots S_{n}$ would not be wrong, the latter truth, when included in our total 'evidence', may overthrow

\footnotetext{
${ }^{34}$ In Plantinga and Tooley, 2008, 241-6, Tooley rejects the view that theistic belief is non-inferentially justified; I discussed the issue in Langtry, 1989. In Tooley, 1991, 102-4, he argued that most arguments for the existence of God 'provide, at best, very tenuous grounds for any conclusion concerning the moral character of any omnipotent and omniscient being who may happen to exist, and almost none of them provide any support for the hypothesis that there is an omnipotent and omniscient being who is also morally perfect'.

${ }^{35}$ Plantinga and Tooley, 2008, 142, 119.
} 
or greatly weaken whatever inductively based justification argument we have had for the proposition God's allowing all of $S_{1}, S_{2}, S_{3} S_{4}, \ldots S_{n}$ would be wrong. ${ }^{36}$

Let me sum up this section. Even if we neglect the questions whether our total evidence includes empirical truths that provide significant support for the existence of God, and whether some people are noninferentially justified in believing (whether firmly or tentatively) that God exists, the foregoing considerations show that the third stage of Tooley's deontological argument from evil gives us little reason to believe that the logical probability that God exists, relative to our total evidence excluding empirical evidence supporting the existence of God, is less than $1 / 10^{9}$ (Tooley's estimate), or even significantly less than the a priori probability that God exists. ${ }^{37}$

\section{An Alternative Analysis of the Inductive Issues}

Since Tooley's argument for MC is unsatisfactory in a number of ways, we need an alternative way of analysing the bearing on theism of the occurrence of a great many particular instances of evil. (Although Tooley surveys a wide variety of kinds of evil in section 4.2 of his main chapter, information about these kinds does not play a role in his argument from evil.) How do the issues look if we avoid talk of rightmaking and wrongmaking properties of actions, but nevertheless try to retain significant connection with $\mathrm{G}_{3}$ or $\mathrm{G}_{3} \mathrm{a}$ ?

\footnotetext{
${ }^{36}$ In Tooley, 2012a, 145-6, he says, briefly, that theodicies typically involve highly disputable moral premises-e.g. the premise that God's not having intervened to facilitate an attempt to assassinate Hitler possesses the rightmaking property Leaving the world one where agents can freely bring about very great evils, and this property outweighs the wrongmaking property choosing not to facilitate the prevention of the suffering and deaths of millions of Holocaust victims. My foregoing remarks about suffering and dysfunction do not commit me to the stated proposition; the central evaluative premise underlying my own partial theodicy is defended in Langtry, 2008, 168-72. In Tooley $2012 \mathrm{~b}$, he discusses some recent theodicies, but what he says does not vitiate the point I am making in the main text. (The argument of my next section does not rely on my partial theodicy.)

${ }^{37}$ It might be thought that if G3a were true then its truth would be a major obstacle or discouraging hindrance to current and future attempts to argue positively in favour of the existence of God. This is not so. After all, incoming evidence frequently leads you, without hesitation, to assign high posterior probabilities to hypotheses whose prior probabilities were very low-e.g. when you came to believe that I wrote the exact sequence of words that happens to make up the first sentence of this footnote.
} 
The specific inductive logic Tooley employs is the one propounded by Carnap (1962). Tooley declares, however, that

philosophers who favor a different inductive logic will be able, I believe, to recast the following argument in their own preferred terms, while readers who do not share my optimism about the existence of an objectively correct inductive logic will be able to reinterpret the argument in terms of subjective probabilities. ${ }^{38}$

Accordingly, he is unlikely to object to the Bayesian framework used to formulate the following line of thought.

Let us consider the bearing of some evidence E2 on the existence of God, in the setting constituted by background evidence that is divided into two parts, E1 and K.

Let $E_{1}$ be a proposition listing all known instances of evil $S_{1}, S_{2}$, $\ldots \mathrm{S}_{\mathrm{n}+\mathrm{m}}$ and saying that it does so. ${ }^{39}$ We know, for example, that very many people died of the Black Death in the fourteenth century. Let us use the name ' $\mathrm{BD} 1$ ' to rigidly designate the first person to do so, ' $\mathrm{BD} 2$ ' to rigidly designate the second, and so on. Various states of affairs involving BD1 will appear amongst the items on the list $S_{1}, S_{2}, \ldots S_{n+m}$, such as BD1's experiencing pain in his or her lymph nodes. ${ }^{40}$

Let $G$ be the proposition There exists an omnipotent, omniscient, and perfectly good person (which I will abbreviate as God exists).

Let $E_{2}$ be the proposition Either God does not exist, or else he does and there is a large subset $\left\{S_{1}, S_{2}, \ldots, S_{n}\right\}$ of $\left\{S_{1}, S_{2}, \ldots, S_{n+m}\right\}$ such that for every member $S_{i}$ of the subset, the known morally relevant truths about $S_{i}$ constitute a strong prima facie case for believing that God should not have allowed $S_{i}$ to be actual.

Let J be the proposition God exists, and there is a large subset $\left\{S_{1}, S_{2}, \ldots, S_{n}\right\}$ of $\left\{S_{1}, S_{2}, \ldots, S_{n+m}\right\}$ such that for every member $S_{i}$ of the subset, the known morally relevant truths about $S_{i}$ constitute a strong prima facie case for believing

38 Plantinga and Tooley, 2008, 135 .

39 There may be no one who can state E1 and recognize E1 thus stated to be true, just as no one can list every person $\mathrm{x}$ such that all your friends know that they have met $\mathrm{x}$. This possibility does not constitute a problem for my argument. After all, Tooley does not need it to be the case that there is someone who, for $\mathrm{n}>10^{9}$, can state a premise listing at least $\mathrm{n}$ states of affairs $S_{1}, S_{2}, S_{3}, S_{4}, \ldots, S_{n}$ which are preventable, respectively, at times $t_{1}, t_{2}, t_{3}, t_{3}$, $t_{4}, \ldots t_{n}$, and are such that, for each $\mathrm{Si}$, choosing not to prevent $\mathrm{Si}$ is an action that, judged by known rightmaking and wrongmaking properties, is prima facie wrong.

${ }^{40}$ Notice that while E1 describes $S_{1}, S_{2}, \ldots, S_{n}$ as evil, Tooley's $G_{3}$ does not. The concept of evil is discussed in Langtry, 2008, 42-6. 
that God should not have allowed $S_{i}$ to be actual. Notice that E2 is logically equivalent to Either $\sim$ Gor J, that G\&E2 entails J, and that J entails E2.

Let $\mathrm{K}$ be all the empirical information shared by all the readers of this book, excluding E1, E2, and propositions that are epistemically posterior to $\mathrm{E} 1 \& \mathrm{E} 2$.

According to Bayes's Theorem,

$$
P(G / E 2 \& E 1 \& K)=\frac{P(G / E 1 \& K) P(E 2 / G \& E 1 \& K)}{P(E 2 / E 1 \& K)}
$$

Consider the right hand side of the foregoing equation-specifically, for now, the term $P\left(E_{2} / G \& E_{1} \& K\right)$. Since $E_{2}$ is logically equivalent to Either $\sim G$ or $J$, and $\mathrm{J}$ is incompatible with $\sim \mathrm{G}, \mathrm{P}\left(\mathrm{E}_{2} / \mathrm{G} \& \mathrm{E} 1 \& \mathrm{~K}\right)=\mathrm{P}(\sim \mathrm{G} /$ $\mathrm{G} \& \mathrm{E} 1 \& \mathrm{~K})+\mathrm{P}(\mathrm{J} / \mathrm{G} \& \mathrm{E} 1 \& \mathrm{~K})$. Since, obviously, $\mathrm{P}(\sim \mathrm{G} / \mathrm{G} \& \mathrm{E} 1 \& \mathrm{~K})=0$, it follows that $\mathrm{P}\left(\mathrm{E}_{2} / \mathrm{G} \& \mathrm{E} 1 \& \mathrm{~K}\right)=\mathrm{P}(\mathrm{J} / \mathrm{G} \& \mathrm{E} 1 \& \mathrm{~K})$.

A very high estimated value for $\mathrm{P}(\mathrm{J} / \mathrm{G} \& \mathrm{E} 1 \& \mathrm{~K})$ is plausible in the light of the fact that $\mathrm{K}$ includes truths about limitations on human cognitive capacities, and about our ignorance about the nature, circumstances, and effects of hugely many known particular bad states of affairs. For example, although we can infer a lot about BD1 from the fact that he or she was a human being who died of the Black Death (together with $\mathrm{K}$ ), we do not know anything about his or her distinctive life-history and personal traits; nor do we know anything about the effects of BD1's dying, and dying in this horrible way, on BD1's relatives, friends, or anyone else. So given G\&K, and given that E1 lists BDi's experiencing various distressing symptoms universal amongst Black Death victims, it is utterly unsurprising that we are aware of truths counting morally against God's allowing this particular state of affairs to occur but are unaware of any truths that count morally in favour of his doing so and that defeat the former truths. At least, it is unsurprising given that $\mathrm{K}$ does not contain various proposed theodicies which would, if God were to exist, justify his allowing there to be severe suffering. ${ }^{41}$

It might be suggested that, given G\&E1\&K, one would expect God to ensure that we were aware of an outweighing moral consideration sufficing

41 This stipulation about $\mathrm{K}$ (which was already implicit in my introduction of $\mathrm{K}$ ) reflects the fact that Tooley's contributions to Plantinga and Tooley, 2008, do not engage with proposed theodicies for suffering. 
to justify God's allowing BD1 to suffer and die as he or she did. But why should we believe this? After all, for all we know, if God exists then the truth that sufficed to justify God in allowing the death of BDi might have only partial overlap with the truth that sufficed to justify God in allowing the death of $\mathrm{BD} 2$, and so on. These truths might themselves be quite complex, in each case involving details of many individuals' life-histories. God might well have many reasons for not providing the readers of this book, in the twenty-first century, with all this detail. ${ }^{42}$

The set of particular evil states of affairs involved in the Black Death of the fourteenth century is a large subset of $\left\{S_{1}, S_{2}, \ldots S_{n}\right\}$ such that for every member of the subset, the known morally relevant truths about $\mathrm{S}_{\mathrm{i}}$ constitute a strong prima facie case for believing that God should not have allowed $S_{\mathrm{i}}$ to be actual. I conclude that $\mathrm{P}(\mathrm{J} / \mathrm{G} \& \mathrm{E} 1 \& \mathrm{~K})$ is high, and therefore that $\mathrm{P}\left(\mathrm{E}_{2} / \mathrm{G} \& \mathrm{E}_{1} \& \mathrm{~K}\right)$ is high.

Let us turn our attention now to $\mathrm{P}\left(\mathrm{E}_{2} / \mathrm{E}_{1} \& \mathrm{~K}\right)$. The foregoing argument can easily be adapted to support the view that $\mathrm{P}\left(\mathrm{E}_{2} / \mathrm{E}_{1} \& \mathrm{~K}\right)$ is high. Is there reason to believe that it is higher than $\mathrm{P}\left(\mathrm{E}_{2} / \mathrm{G} \& \mathrm{E}_{1} \& \mathrm{~K}\right)$ ? One putative reason has already been foreshadowed, and in effect dismissed: given that God exists, for each $S_{\mathrm{i}}$ we would expect him to provide us with evidence which defeated the strong prima facie case for believing that God should not have allowed $\mathrm{S}_{\mathrm{i}}$ to be actual, whereas if we were not to assume that God exists then we would not expect to possess evidence which would (if God were to exist) justify him in allowing $S_{\mathrm{i}}$ to be actual. In the absence of some better proposed reason-I am aware of none-we have no reason to believe that $\mathrm{P}\left(\mathrm{E}_{2} / \mathrm{E}_{1} \& \mathrm{~K}\right)>\mathrm{P}\left(\mathrm{E}_{2} / \mathrm{G} \& \mathrm{E} 1 \& \mathrm{~K}\right)$, and therefore no reason to believe $\mathrm{P}\left(\mathrm{G} / \mathrm{E}_{2} \& \mathrm{E} 1 \& \mathrm{~K}\right)<\mathrm{P}(\mathrm{G} / \mathrm{E} 1 \& \mathrm{~K})$, i.e. that E2 disconfirms G.

The foregoing probabilistic analysis does not purport to establish that known truths concerning evil do not provide the basis for a strong objection to the existence of God. I claim instead that a specific, highly schematic argument I constructed-one that mirrors Tooley's deontological argument as closely as is feasible while avoiding the problems I have

\footnotetext{
42 The foregoing two paragraphs do not involve sceptical theism. For the considerations sufficing for the purposes of my argument do not pertain to general human cognitive limitations with respect to value and thus God's reasons for action but instead pertain to 'our' unsurprising de facto ignorance of empirical details and accordingly of reasons for action by God (or other, finite but powerful and well-placed agents) which might be generated by such empirical details.
} 
highlighted in earlier sections-does not constitute a strong objection to the existence of God.

\section{References}

Armstrong, D. M. 1978. A Theory of Universals: Universals and Scientific Realism, ii. Cambridge: Cambridge University Press.

Carnap, Rudolf. 1962. Logical Foundations of Probability, 2nd edn. Chicago: University of Chicago Press.

Langtry, Bruce. 1989. 'Properly Unargued Belief in God.' International Journal for the Philosophy of Religion, 26: 129-54.

Langtry, Bruce. 2008. God, the Best, and Evil. Oxford: Clarendon Press.

Plantinga, Alvin and Tooley, Michael. 2008. Knowledge of God. Oxford: Blackwell Publishing.

Rowe, W. L. 1979. 'The Problem of Evil and Some Varieties of Atheism.' American Philosophical Quarterly, 16: 335-41.

Rowe, W. L. 1996. 'The Evidential Argument from Evil: A Second Look.' In Daniel Howard-Snyder (ed.), The Evidential Argument from Evil. Bloomington, IN: Indiana University Press, 262-85.

Tooley, Michael. 1991. 'The Argument from Evil.' Philosophical Perspectives, 5: 89-134.

Tooley, Michael. 2012a. 'Inductive Logic and the Probability that God Exists: Farewell to Sceptical Theism.' In Jake Chandler and Virginia S. Harrison (eds), Probability in the Philosophy of Religion. Oxford: Oxford University Press, 144-66.

Tooley, Michael. 2012b., 'The Problem of Evil.' Online in The Stanford Encyclopedia of Philosophy, <http://plato.stanford.edu/entries/evil $>$ (accessed July 2014). 